\title{
НЕМОНЕТАРНЫЙ КАНАЛ ВЗАИМОСВЯЗИ МЕЖДУНАРОДНОЙ МИГРАЦИИ И КАЧЕСТВА ПИТАНИЯ ДОМОХОЗЯЙСТВ МИГРАНТОВ (НА ПРИМЕРЕ РЕСПУБЛИКИ АРМЕНИЯ)
}

\author{
ВАЛЕРИЯ ОКСИНЕНКО
}

\begin{abstract}
В статье анализируется миграция как фактор качества питания оставшихся на родине членов домохозяйства мигранта. Для оценки качества питания в исследовании на данных Интегрированного обследования домохозяйств Республики Армения за 2013-2017 г2. рассчитывается комплексный индекс качества питания на базе методологии индекса НЕІ Центра пищевой политики Департамента сельского хозяйства США 2015 г. В результате проведения регрессионного анализа и анализа на уровне средних выявляется, что на качество питания домохозяйств отрицательно влияет наличие мигрантов в целом, причем более значительный вклад вносят вернувшиеся мигранты. Исходя из того, что различия в доходах не позволяют объяснить имеющуюся разнииу, делается вывод о наличии немонетарного канала воздействия мигращии на питание в домохозяйстве. Также в работе были проверены существуюшие $в$ литературе выводы о положительном влиянии на качество питания домохозяйств наличия в нем женщин, пожилых и детей, проживания в больших городах, высокого уровня образования и дохода - все взаимосвязи подтвердились для домохозяйств Республики Армения. Дополнительным направлением исследования стало введение в анализ субъективной оиенки домохозяйствами своего финансового состояния: так, домохозяйства, позиционирующие себя как более бедные, имеют более высокие значения индекса качества питания, чем те, кто относит себя к среднему классу или к богатым. Обнаруженные различия приводят к выводу о том, что качество питания не входит в систему ключевых иенностей в рассматриваемом обществе, так как при наличии возможности выбирать стиль питания домохозяйства делают выбор в худиую сторону.
\end{abstract}

Ключевые слова: миграция, Армения, питание домохозяйств, возвратная миграция, благосостояние домохозяйств мигрантов.

\section{ВВЕДЕНИЕ}

Участие в международной миграции вносит изменения в жизнь не только самого мигранта, но и в жизни членов его домохозяйства, остающихся на родине: от уровня образования детей (Marchetta, Sim 2021: 13; Shen, Hu, Hannum 2021: 12) до величины вкладов в защиту лесов (Xie et al. 2019: 67). Так как большинство стран, активно участвующих в миграции, характеризуются достаточно низким уровнем благосостояния населения, отдельного внимания в этом контексте заслуживает вклад миграции членов домохозяйства в качество потребления остальных его членов, оставшихся на родине. Качество питания - не только ключевой индикатор здоровья населения, но, по данным некоторых исследований, оно может определять социальное положение индивида или домохозяйства в обществе (Darmon, Drewnowski 2008: 1112) и выступать как одна из прокси качества жизни (Huffman, Rizov 2018: 13).

ВАЛЕРИЯ ГЕННАДЬЕВНА ОКСИНЕНКО (leraoksinenko@gmail.com), МОСКОВСКИЙ ГОСУДАРСТВЕННЫЙ УНИВЕРСИТЕТ ИМЕНИ М.В. ЛОМОНОСОВА, РОССИЯ.

СТАТЬЯ ПОДГОТОВЛЕНА В РАМКАХ ПРОЕКТА, ФИНАНСИРУЕМОГО РФФИ, № 20-310-90017.

СТАТЬЯ ПОСТУПИЛА В РЕДАКЦИЮ В СЕНТЯБРЕ 2021 Г. 
Влияние миграции на качество питания домохозяйства мигранта изучено слабо, а результаты имеющихся работ достаточно противоречивы. В исследовании, проведенном для домохозяйств в Индии, было выявлено более низкое качество рациона детей мигрантов в сравнении с немигрантами (Lei, Desai, Chen 2020: 550-552). В другом исследовании для той же страны рассматривались девушки из сельской местности, которые уезжают из родных населенных пунктов, когда выходят замуж за жителей других городов и стран. Результаты показали, что качество питания домохозяйств таких девушек после их отъезда улучшается в первую очередь за счет исчезновения эпизодов голода (Rosenzweig, Stark 1989: 924-925). В более раннем исследовании для Таджикистана также обнаружилась положительная корреляция рассматриваемых факторов: не только качество питания, но и показатели здоровья оставшихся на родине детей мигрантов становились выше, чем у детей немигрантов (Azzarri, Zezza 2011: 66).

В рамках данного исследования оценивается воздействие участия в международной миграции на качество питания домохозяйств мигрантов, оставшихся на родине, на примере Республики Армения.

Выбор страны обусловлен двумя причинами. С одной стороны, Республика Армения является развивающейся страной, которая активно участвует в международной миграции и с 2015 г. является членом Евразийского экономического союза (ЕАЭС), что привело к образованию единого рынка труда с другими странами-членами, включая Россию. Поэтому, хотя исследование проводится на данных по Армении, его выводы могут быть использованы для близких по экономическим характеристикам стран региона.

С другой стороны, по мнению экспертов в области нутрициологии в Армении, миграция отрицательно влияет на качество потребления армян: их рацион в настоящее время из «средиземноморского» (с большим содержанием овощей, фруктов, злаков и оливкового масла) под влиянием других культур и снижения роли сельского хозяйства в производстве превратился в более разбалансированный (Bedrosian 2019). Таким образом, высказывается предположение о негативном эффекте миграции для качества питания домохозяйств через немонетарный канал привнесения новых привычек в питание возвратными мигрантами.

Данный вопрос не исследован в академической литературе, но является крайне актуальным в свете возросшего интереса исследователей к немонетарному каналу воздействия миграции на членов домохозяйств мигрантов. Если раньше в большинстве работ в качестве ключевого фактора воздействия отмечались денежные трансферты мигрантов (Bansak, Chezum 2009: 148; Mansour, Chaaban, Litchfield 2011: 846), то в последние годы все чаще предпринимаются попытки отследить влияние иных факторов. Так, на уровень образования детей мигрантов из Камбоджи в первую очередь негативно влияет отсутствие родителей, уехавших в другую страну (Marchetta, Sim 2021: 13). В другой работе отмечается, что отсутствие отцов-мигрантов и рост роли матери в воспитании негативно сказываются на формировании человеческого капитала детей в Китае (Shen, Hu, Hannum 2021: 12). Но обнаруживаются и положительные каналы воздействия миграции: так, рост показателей здоровья детей в Мексике исследователи связывают с ростом медицинских познаний их матерей, вернувшихся из миграции в США. Однако сами авторы 
отмечают, что уровень влияния этого канала нуждается в дополнительном уточнении (Hildebrandt et al. 2005: 283).

Таким образом, фокус данного исследования - получить комплексную оценку воздействия международной миграции на питание членов домохозяйства мигранта в Республике Армения и подтвердить, что это воздействие в первую очередь осуществляется через немонетарный канал.

Статья включает следующие разделы:

- $\quad$ описание данных;

- методология оценки качества питания;

- анализ различий в качестве потребления продуктов питания между домохозяйствами с мигрантами и без мигрантов;

- регрессионный анализ социально-экономических факторов, влияющих на индекс качества питания;

- взаимосвязь качества питания и субъективной оценки уровня благосостояния домохозяйства;

- заключение.

\section{ДАННЫЕ}

Эмпирической основой исследования являются данные Интегрированного обследования условий жизни домашних хозяйств в Республике Армения (далее - Обследование), которое проводится ежегодно с 2001 г. (последние результаты опубликованы за 2018 г.).

Уникальность данных в сравнении с данными аналогичных обследований в других странах ЕАЭС, включая Россию, заключается в их высокой подробности, значительном охвате и наличии разделов, связанных с миграцией и питанием членов домохозяйств. Размер выборки Обследования варьируется от 5 до 8 тыс. домохозяйств в городских и сельских районах, что составляет около 20 тыс. респондентов ежегодно. Так как в 2015 г. Армения вступила в состав ЕАЭС, что потенциально могло повлиять на структуру питания домохозяйств, мы берем данные за период 2013-2017 гг. с серединой в 2015 г., чтобы выявить предполагаемые эффекты. Анкета обследования содержит вопросы, позволяющие оценить качество потребления домохозяйства, а также ряд вопросов, ответы на которые позволяют охарактеризовать домохозяйства по различным параметрам, в частности, по численности домохозяйства, среднедушевому доходу, доле женщин, детей и пожилых в домохозяйстве, наличию мигрантов и др.

Помимо участия в общем опросе, домохозяйствам предлагается в течение месяца вести дневник питания, в котором они отмечают все потребленные продукты, произведенные самостоятельно или приобретенные, с указанием объемов их потребления. Распределение домохозяйств по месяцам года равномерно и случайно, единица учета потребления - домохозяйство. Полный перечень продуктов питания, учитываемый в рамках анкетирования, соответствует Классификации индивидуального потребления 
по целям Европейского Статистического комитета (2012) и включает исключительно продукты питания и различные виды напитков ${ }^{1}$.

\section{МЕТОДОЛОГИЯ ОЦЕНКИ КАЧЕСТВА ПИТАНИЯ}

В академической литературе для оценки качества питания используется несколько подходов. Наиболее распространенной является оценка общей питательности: качество рациона оценивается, исходя из количества потребляемых с пищей витаминов и минералов (Burggraf et al. 2015: 186-187). Как правило, подобного рода исследования возможны только на небольшой выборке в силу необходимости в очень детальных данных.

В большинстве работ выбирается прокси качества питания: положительное (в большинстве случаев это овощи и фрукты) (Bernstein et al. 2010: 1198; Azagba, Sharaf 2011: 2; Dave, Kelly 2012: 255) или отрицательное (чаще всего алкоголь) (Massin, Kopp 2014: 804; Mangiavacchi, Piccoli 2018: 92). Такой подход удобен с точки зрения расчетов и масштабирования, но не дает комплексной оценки качества рациона.

Еще один подход сводится к расчету индекса качества питания (ИКП), который представляет собой комплексный показатель, учитывающий разные аспекты питания населения и группы микро- и макронутриентов, включенных в рацион (Мартинчик 2019: 69). По нашему мнению, он совмещает в себе преимущества обоих описанных выше подходов: с одной стороны, легко масштабируется, с другой - позволяет учесть особенности рациона респондентов в целом. Сложность подхода - в необходимости создания и обработки детальной анкеты питания населения, поэтому расчет и использование ИКП в научных исследованиях характерен для стран, где индекс считается на государственном уровне (например, в США (Guenther et al. 2009: 2003-2004)). Данные Обследования позволяют рассчитать такой индекс для домохозяйств, что уже было проделано автором в более ранней работе (Оксиненко 2021), он же будет использован для оценки качества питания домохозяйств Армении в данном исследовании.

В предложенной анкете домохозяйства отмечали продукты питания, которые они потребляли (без детализации на отдельных членов домохозяйства) в течение месяца, с указанием их количества, что в итоговых данных представлено в виде суммарных показателей по отдельным продуктам (2013 г.) или группам продуктов одного типа (20142017 гг. $)^{2}$. Объемы среднедушевого потребления основных групп продуктов приведены в таблице П1 Приложения: величины ежемесячного среднедушевого потребления основных продуктовых групп имеют высокую вариацию, однако соответствуют ожидаемым для Армении и позволяют охарактеризовать данные как достаточно полные и релевантные целям исследования.

Такого рода данные позволяют рассчитать интегральный индекс качества питания домохозяйств: информация о потреблении дается на уровне домохозяйств, причем очень детально, в отличие от аналогичных данных в других странах. Вариация в качестве питания

\footnotetext{
${ }^{1}$ URL: https://microdata.worldbank.org/index.php/catalog/3591/related-materials

${ }^{2}$ URL: https://microdata.worldbank.org/index.php/catalog/3591/related-materials 
состоит из различий между домохозяйствами и внутри их, и при таком подходе, безусловно, нельзя оценить вариацию внутри домохозяйства, хотя она может быть значительной. Однако вопрос различия качества питания между домохозяйствами также сложно переоценить, особенно в контексте влияния миграции на качество питания в домохозяйстве.

Так как на государственном уровне ИКП ни для индивидов, ни для домохозяйств Армении не рассчитывается, для оценки качества питания был построен индекс, в основу которого был положен индекс HЕI Центра пищевой политики Департамента сельского хозяйства США 2015 г. ${ }^{3}$. Хотя исходный индекс рассчитывается для индивидуумов, а не домохозяйств, его выбор в качестве основы обусловлен структурой данных о питании домохозяйств Армении, а также стремлением выбрать стандарт для сопоставления качества питания домохозяйств в рассматриваемые годы.

HЕI представляет собой перечень индикаторов качественного питания с системой их перевода в баллы. После последнего обновления индекс включает 13 компонентов. Распределение величин потребления каждого компонента оценивается от 0 до 5 баллов или от 0 до 10 баллов в зависимости от значимости рассматриваемой группы в рационе. Первая группа из девяти компонентов представлена индикаторами адекватности потребления (полезными для рациона продуктами). Она оценивает в баллах рацион с точки зрения соответствия рекомендациям по потреблению наиболее важных групп пищевых продуктов в США: зерновых, овощей, фруктов, белковых и молочных продуктов и др. Перевод в баллы основан на количестве потребляемых порций указанных групп продуктов в этой же стране.

Вторая группа из четырех компонентов - это индикаторы ограничения (группа продуктов и нутриентов, потребление которых нежелательно). Они включают потребление насыщенных жирных кислот (НЖК) в процентах от калорийности рациона, а также абсолютные величины потребления добавленных сахаров и натрия (Na). После расчета оценки в баллах каждого из индикаторов-компонентов путем суммирования выводится интегральный индекс, который изменяется от 0 до 100 баллов. Подробнее с методикой расчета индекса можно ознакомиться в более ранней статье автора (Оксиненко 2021).

С 2014 года учет продуктов питания в Интегрированном обследовании условий жизни домашних хозяйств в Республике Армения стал основываться на Классификации индивидуального потребления по целям Европейского Статистического комитета ${ }^{4}$ и продуктовые группы начали представляться в частично агрегированном формате. В результате в методику расчета НЕI были внесены небольшие изменения (см. примечания к таблице 1). Структура ИКП для домохозяйств Армении представлена в таблице 1.

\footnotetext{
${ }^{3}$ URL: https://www.fns.usda.gov/healthy-eating-indexhei\#: :text=The\%20Healthy\%20Eating\%20Index\%20(HEI,the\%20Dietary\%20Guidelines\%20for\%20Americans. ${ }^{4}$ URL: https://microdata.worldbank.org/index.php/catalog/3591/related-materials
} 


\section{Таблица 1. Компоненты и балльная оценка индекса качества питания для домохозяйств Республики Армения}

\begin{tabular}{|c|c|c|c|}
\hline $\begin{array}{l}\text { Частные индексы } \\
\text { потребления }\end{array}$ & $\begin{array}{l}\text { Максимум } \\
\text { баллов }{ }^{1}\end{array}$ & $\begin{array}{l}\text { Критерий получения } \\
\text { максимального балла }\end{array}$ & $\begin{array}{l}\text { Критерий получения } \\
\text { минимального балла }\end{array}$ \\
\hline \multicolumn{4}{|c|}{ Индикаторы адекватного потребления: } \\
\hline $\begin{array}{l}\text { Фрукты, общее } \\
\text { количество }\end{array}$ & 5 & $\geq 0,8$ порций (чашек) на 1000 ккал & Отсутствие в рационе \\
\hline $\begin{array}{l}\text { Фрукты в натуральном } \\
\text { виде }\end{array}$ & 5 & $\geq 0,4$ порций (чашек) на 1000 ккал & Отсутствие в рационе \\
\hline Овощи, общее количество ${ }^{4}$ & $10^{5}$ & $\geq 1,3$ порций (чашек) на 1000 ккал 5 & \multirow{2}{*}{$\begin{array}{l}\text { Отсутствие в рационе } \\
\text { Отсутствие в рационе }\end{array}$} \\
\hline $\begin{array}{l}\text { Продукты из цельного } \\
\text { зерна }\end{array}$ & 10 & $\geq 1,5$ порций (чашек) на 1000 ккал & \\
\hline Молочные продукты ${ }^{6}$ & 10 & $\geq 1,3$ порций (чашек) на 1000 ккал & \multirow{2}{*}{$\begin{array}{l}\text { Отсутствие в рационе } \\
\text { Отсутствие в рационе }\end{array}$} \\
\hline $\begin{array}{l}\text { Белоксодержащие } \\
\text { продуктыт }^{7}\end{array}$ & 5 & $\geq 2,5$ порций (чашек) на 1000 ккал & \\
\hline Морепродукты ${ }^{7,8}$ & 5 & $\geq 0,8$ порций (чашек) на 1000 ккал & \multirow{2}{*}{$\begin{array}{c}\text { Отсутствие в рационе } \\
\text { (ПНЖК + МНЖК) / } \\
\text { НЖК } \leq 1,2\end{array}$} \\
\hline Жирные кислоты ${ }^{9}$ & 10 & НЖК $\geq 2,5$ & \\
\hline \multicolumn{4}{|c|}{ Индикаторы ограничения потребления: } \\
\hline $\begin{array}{l}\text { Рафинированные зерновые } \\
\text { продукты }\end{array}$ & 10 & $\leq 1,8$ унций на 1000 ккал & $\geq 4,3$ унций на 1000 ккал \\
\hline Натрий ${ }^{12}$ & 10 & $\leq 1,1$ г на 1000 ккал & \multirow{3}{*}{$\begin{array}{l}\geq 2,0 \text { г на } 1000 \text { ккал } \\
\geq 26 \% \text { энергии суточного } \\
\text { рациона } \\
\geq 16 \% \text { энергии суточного } \\
\text { рациона }\end{array}$} \\
\hline Сахара добавленные ${ }^{13}$ & 10 & $\leq 6,5 \%$ энергии суточного рациона & \\
\hline НЖК & 10 & $\leq 8 \%$ энергии суточного рациона & \\
\hline
\end{tabular}

Источник: Составлено автором на основе (Krebs-Smith et al. 2015).

Примечания:

ПНЖК - полиненасыщенные жирные кислоты;

МНЖК - мононенасыщенные жирные кислоты;

НЖК - насыщенные жирные кислоты;

1. балль между максимальным и минимальным значением распределяются пропоричонально;

2. включает 100\%-ные фруктовые соки;

3. включает все виды фруктов, за исключением соков;

4. включает все бобовые (бобы и горох);

5. рассчитывается как сумма оценок потребления овощей, зелени и бобовых, так как с 2014 г. эти виды овощных не учитываются отдельно;

6. включает все молочные продукты - питьевое молоко, йогурты, сыры и обогащенные соевые напитки;

7. не включают бобовые (бобы и горох), в отличие от расчетов НEI;

8. не включает орехи, семена, соевые продукты (без напитков), бобы и горох, в отличие от расчетов $H E I$;

9. отношение суммы ПНЖК + МНЖК к НЖК; НЖК рассчитывается как суммарное потребление продуктов с высоким содержанием НЖК (жирное мясо и жиры животного происхождения);

10. ПНЖК рассчитывается как суммарное потребление продуктов с высоким содержанием ПНЖК;

11. МНЖК рассчитывается как суммарное потребление продуктов с высоким содержанием МНЖК (вместе с ПНЖК сюда включены различные виды растительных масел);

12. включает все виды сухих специй (черный перец, чабрец и др.), так как они представлены единой группой в данных Обследования;

13. включает только сахар, указанный участниками обследования как отдельную продуктовую категорию, а также сладкие напитки (компоты, сладкие газированные напитки), варенья, крепкий алкоголь, различные виды не мучных десертов.

Каждой продуктовой позиции была присвоена калорийность, рассчитанная как среднее значение калорийностей ключевых продуктов, входящих в данную группу (с учетом ее определения в Классификации индивидуального потребления по целям 
Европейского Статистического комитета ${ }^{5}$ ), объемы потребления продуктов питания были переведены в представленные в таблице 1 единицы измерения. Средние показатели и границы значений ИКП для домохозяйств Армении за 2013-2017 гг. представлены в таблице 2. При построении средних здесь и далее единицей наблюдения является домохозяйство, чтобы исключить влияние величины домохозяйства на средние значения.

Таблица 2. Значения индекса качества питания для домохозяйств Армении, 2013-2017

\begin{tabular}{c|c|c|c|c|c}
\hline Год & Число наблюдений & Среднее значение & $\begin{array}{c}\text { Границы доверительного } \\
\text { интервала (5\%) }\end{array}$ & Минимум & Максимум \\
\hline 2013 & 5184 & 63,89 & $63,693-64,078$ & 34,88 & 86,41 \\
2014 & 5184 & 65,00 & $64,826-65,178$ & 35,61 & 86,92 \\
2015 & 5184 & 65,63 & $65,452-65,804$ & 40,25 & 86,63 \\
2016 & 5182 & 65,99 & $65,805-66,170$ & 42,86 & 84,89 \\
2017 & 7776 & 65,21 & $65,057-65,362$ & 35,00 & 87,58 \\
\hline
\end{tabular}

Источник: Расчеты автора на основе Комплексного обследования уровня жизни домашних хозяйств в Республике Армения.

Полученные значения индекса являются достаточно высокими: по данным Центра пищевой политики Департамента сельского хозяйства США 2015 г. за 2014-2015 гг. среднее значение индекса HEI для американцев составляло 59, что ниже, чем у армянских домохозяйств в те же годы ${ }^{6}$, хотя в данном случае полная сопоставимость не обеспечивается из-за изменений, внесенных в методику расчета индекса, а также разных условий жизни населений двух стран. Однако, рассматривая изменения значения индекса только для Армении, легко заметить, что в 2013-2016 гг. наблюдался стабильный рост ИКП, причем увеличивались не только средние, но и минимальные значения. Важно отметить, что результат 2017 г. здесь и далее мы будем считать не вполне сопоставимым: в этом году наблюдается значительный рост объема выборки, что может в какой-то степени влиять на исходные характеристики, и, соответственно, на итоговую оценку индекса питания.

Существенными для оценки качества питания армянских домохозяйств является не только итоговое значение ИКП, но и его частные показатели, приведенные в таблице 1. Средние значения частных индексов потребления различных продуктовых групп по годам представлены в таблице 3: в левом столбце перечислены 12 компонентов ИКП (в скобках максимально возможная оценка в баллах для каждого индекса) с указанием, к какой группе индикаторов (адекватного потребления или ограничения) они относятся. Чем выше значение каждого частного показателя, тем выше качество потребления армянских домохозяйств по этому параметру.

Наиболее низкие показатели из года в год наблюдаются по четырем компонентам: «Продукты из цельного зерна» (здесь учитываются в основном различные виды круп), «Морепродукты» (рыба и другие виды морепродуктов), «Жирные кислоты» (соотношение потребления «полезных» ненасыщенных жиров, таких как растительные масла,

\footnotetext{
${ }^{5}$ URL: https://microdata.worldbank.org/index.php/catalog/3591/related-materials

${ }^{6}$ URL: https://www.fns.usda.gov/healthy-eating-index-

hei\#: :text=The $\% 20$ Healthy\%20Eating\%20Index \%20(HEI,the\%20Dietary\%20Guidelines\%20for\%20Americans
} 
к «неполезным» насыщенным жирным кислотам, содержащимся в продуктах животного происхождения), «Рафинированные зерновые продукты» (хлеб и мучные изделия). Объяснение низкого уровня потребления рыбы и морепродуктов связано с тем, что Армения не имеет выхода к морю, высокий уровень потребления мучных продуктов объясняется культурой потребления в стране, где большинство национальных блюд содержит хлеб в качестве основного компонента. Что касается оставшихся двух компонентов, то они вполне могут свидетельствовать о негативных тенденциях в структуре рациона.

Таблица 3. Средние значения частных индексов качества питания для домохозяйств Армении, 2013-2017

\begin{tabular}{|c|c|c|c|c|c|}
\hline Компоненты (max значение) & 2013 & 2014 & 2015 & 2016 & 2017 \\
\hline \multicolumn{6}{|l|}{ Индикаторы адекватного потребления: } \\
\hline Фрукты, общее количество (5) & 3,96 & 4,01 & 4,11 & 4,19 & 4,12 \\
\hline Фрукты в натуральном виде (5) & 4,10 & 4,12 & 4,23 & 4,29 & 4,27 \\
\hline Овощи, общее количество (10) & 9,99 & 9,99 & 9,99 & 9,99 & 9,98 \\
\hline Продукты из цельного зерна (10) & 4,26 & 3,66 & 3,58 & 3,86 & 3,42 \\
\hline Молочные продукты (10) & 8,70 & 8,85 & 9,01 & 9,07 & 9,09 \\
\hline Белоксодержащие продукты (5) & 2,61 & 2,59 & 2,59 & 2,63 & 2,77 \\
\hline Морепродукты (5) & 0,95 & 0,79 & 0,71 & 0,81 & 0,90 \\
\hline Жирные кислоты (10) & 1,26 & 2,97 & 3,37 & 3,20 & 2,87 \\
\hline \multicolumn{6}{|l|}{ Индикаторы ограничения потребления: } \\
\hline Рафинированные зерновые продукты (10) & 0 & 0 & 0 & 0 & 0 \\
\hline Натрий (10) & 9,97 & 9,96 & 9,98 & 9,98 & 10 \\
\hline Сахара добавленные (10) & 9,33 & 8,59 & 8,44 & 8,41 & 8,53 \\
\hline НЖК (10) & 8,55 & 9,44 & 9,61 & 9,56 & 9,27 \\
\hline
\end{tabular}

Источник: Расчеты автора на основе Комплексного обследования уровня жизни домашних хозяйств $в$ Республике Армения.

Примечание: НЖК - насыщенные жирные кислоты.

Одновременно стоит отметить высокие показатели частных индексов «Фрукты в натуральном виде» и «Овощи»: с одной стороны, это снова обусловлено пищевой культурой страны, с другой - свидетельствует о том, что продукты сельскохозяйственного производства все еще играют важную роль в рационе армянских домохозяйств.

Построенный ИКП используется в данном исследовании в качестве зависимой переменной для оценки вклада миграции и других социально-экономических факторов в качество потребления домохозяйств.

\section{АНАЛИЗ РАЗЛИЧИЙ В КАЧЕСТВЕ ПОТРЕБЛЕНИЯ ПРОДУКТОВ ПИТАНИЯ МЕЖДУ ДОМОХОЗЯЙСТВАМИ С МИГРАНТАМИ И БЕЗ МИГРАНТОВ}

\section{Анализ на уровне средних различий в качестве потребления домохозяйств с мигрантами и без мигрантов}

Для оценки различий в качестве питания между домохозяйствами на уровне средних значений все домохозяйства были поделены на тех, кто имеет и не имеет мигрантов (таблица 4). В качестве домохозяйств с мигрантами учитывались те, кто имеет 
отсутствующих, а также вернувшихся мигрантов, участвовавших в миграции любого типа на протяжении трех лет до момента проведения опроса в раундах 2013-2016 гг. и на протяжении года в раунде 2017 г. По данным Обследования, в среднем по всем годам доля домохозяйств с мигрантами от общего числа домохозяйств равнялась 40,83\%. При этом от общего числа респондентов только порядка 20\% участвуют в миграции.

Таблица 4. Количество домохозяйств, имеющих и не имеющих мигрантов в своем составе, с учетом числа домохозяйств, имеющих мигрантов в России, 2013-2017

\begin{tabular}{c|c|c|c|c}
\hline Год & Есть мигрант & $\begin{array}{c}\text { Есть мигрант в } \\
\text { России }\end{array}$ & $\begin{array}{c}\text { Доля дх с мигрантами в России в общем числе } \\
\text { дх с мигрантами, \% }\end{array}$ & Нет мигранта \\
\hline 2013 & 2816 & 878 & 31,1790 & 2368 \\
2014 & 1320 & 915 & 69,3182 & 3864 \\
2015 & 2843 & 896 & 31,5160 & 2341 \\
2016 & 2852 & 985 & 34,5372 & 2330 \\
2017 & 1809 & 1290 & 71,3101 & 5967 \\
\hline
\end{tabular}

Источник: Расчеты автора на основе Комплексного обследования уровня жизни домашних хозяйств в Республике Армения.

Примечание: $\partial x-$ домохозяйство.

Таблица 5. Среднее значение ИКП домохозяйств Армении в зависимости от наличия или отсутствия мигрантов, а также направления миграции, 2013-2017

\begin{tabular}{c|c|r|r|r}
\hline Год & $\begin{array}{c}\text { В домохозяйстве нет } \\
\text { мигрантов }\end{array}$ & $\begin{array}{c}\text { В домохозяйстве есть } \\
\text { мигранты }\end{array}$ & Мигрант не в России & Мигрант в России \\
\hline \multirow{2}{*}{2013} & 64,090 & $63,245^{* *}$ & $(0,000)$ & $62,760^{*}$ \\
& & $64,638^{*}$ & 63,663 & $(0,012)$ \\
2014 & 65,1289 & $(0,017)$ & 64,429 \\
& 65,889 & $64,785^{* *}$ & & $(0,559)$ \\
2015 & 66,343 & $(0,000)$ & 64,651 & $64,437 * *$ \\
& & $64,975^{* *}$ & $(0,006)$ \\
2016 & 65,401 & $64,585^{* *}$ & 65,631 & $64,449^{* *}$ \\
2017 & $(0,000)$ & 64,676 & $(0,000)$ \\
& & & 64,377 \\
\hline
\end{tabular}

Источник: расчеты автора на основе Комплексного обследования уровня жизни домашних хозяйств в Республике Армения

Примечание: В скобках обозначена вероятность того, что различие между средними равно 0 (результат проверки гипотезы на статистическую значимость различий средних);

значимость оченок на различных уровнях: * - уровень значимости полученного различия на 5\%-ном уровне, **_на 1\%-ном уровне.

Отдельного внимания заслуживают домохозяйства, имеющие мигрантов в России, как в основной принимающей стране для мигрантов из Армении: в период 2013-2017 гг. доля мигрантов, уезжающих в Россию, варьировалась от 30 до 70\% от общего числа, однако важно отметить, что в абсолютных показателях число мигрантов, уезжающих в Россию, растет (таблица 4). Резкое сокращение общего числа мигрантов в 2014 и 2017 г. вероятнее всего связано с факторами общеэкономического характера: в эти годы страна демонстрировала относительно высокие в сопоставлении с предшествующими годами 
показатели роста ВВП 7 , что позволило отложить миграцию тем, кто мог это сделать. Склонность к миграции в Россию оказывается неэластичной; это может быть обусловлено тем, что для некоторых слоев населения трудовая миграция в Россию является основным средством заработка.

Результат анализа участия домохозяйства в миграции и качества питания в нем на уровне средних соответствует существующим в литературе выводам: в среднем для домохозяйств с мигрантами ИКП на 0,6 пункта ниже, чем для домохозяйств без мигрантов. В то же время оценка различий по направлениям миграции не дала столь однозначных результатов: хотя в целом средние показатели ИКП выше у домохозяйств с мигрантами не в России, для 2014 и 2017 г. различия оказались статистически незначимыми, что подчеркивает необходимость применения иных методов анализа (таблица 5).

Предположение о том, что качество питания снижается именно за счет вернувшихся мигрантов, в целом на данном уровне анализа не подтвердилось: статистически значимые результаты получены только для 2014 и 2017 г., в то время как в остальные годы мы видим практически равные значения показателей для двух групп домохозяйств, что позволяет предположить незначительный уровень различий (таблица 6).

\section{Таблица 6. Среднее значение ИКП домохозяйств Армении в зависимости от наличия вернувшихся мигрантов, 2013-2017}

\begin{tabular}{c|c|c}
\hline Год & Есть невернувшиеся мигранты & Есть вернувшиеся мигранты \\
\hline \multirow{2}{*}{2013} & \multirow{2}{*}{63,402} & 63,597 \\
& & $(0,469)$ \\
2014 & 64,885 & $63,926^{*}$ \\
& & $(0,012)$ \\
2015 & 64,993 & 65,249 \\
& & $(0,334)$ \\
2016 & 65,154 & 65,550 \\
& & $(0,135)$ \\
2017 & 65,087 & $63,810^{* *}$ \\
\end{tabular}

Источник: Расчеты автора на основе Комплексного обследования уровня жизни домашних хозяйств в Республике Армения.

Примечание: В скобках обозначена вероятность того, что различие между средними равно 0 (результат проверки гипотезы на статистическую значимость различий средних;

значимость оценок на различных уровнях: * - на 5\%-ном, ** - на 1\%-ном.

Результаты приведенных сопоставлений в целом подтверждают наличие взаимосвязи между участием домохозяйства в миграции и качеством его питания. Однако механизм этого влияния на данном уровне анализа остается неясным, в связи с чем мы еще раз вернемся к факторам миграции и качества питания в регрессионном анализе.

\footnotetext{
${ }^{7}$ URL: https://data.worldbank.org/indicator/NY.GDP.MKTP.KD.ZG?locations=AM 


\section{Анализ на уровне средних различий в качестве потребления домохозяйств в зависимости от прочих социально-экономических факторов}

Для анализа методом наименьших квадратов (МНК-регрессии) на объединенной выборке с ИКП домохозяйств в качестве зависимой переменной необходимо учесть иные социальноэкономические факторы, влияющие на качество питания.

В литературе данный вопрос изучен достаточно хорошо для развитых стран. В исследовании влияния социальных факторов на потребление фруктов и овощей канадскими домохозяйствами было выявлено, что женатые и имеющие детей люди потребляют овощи и фрукты чаще, чем одинокие и не имеющие детей соответственно. Кроме этого, более высокий уровень образования также положительно ассоциируется с частотой потребления овощей и фруктов (Azagba, Sharaf 2011: 2). Полученные результаты были повторены в масштабном исследовании диеты американцев и англичан, в котором рассматривалась частота потребления овощей респондентами (Dave, Kelly 2012: 255; Hiza et al. 2013: 298). Важным фактором различия в качестве питания является также уровень дохода. Так, в комплексном исследовании качества питания наиболее бедных и наиболее богатых слоев населения США была обнаружена прямая корреляция между расходами на продукты питания и качеством потребления у бедных домохозяйств (Bernstein et al. 2010: 1199). Еще в одной работе было доказано, что представители низших социальных классов в США питаются хуже с точки зрения структуры питания, чем их более богатые сограждане (Darmon, Drewnowski 2008: 113).

Таблица 7. Среднее значение ИКП домохозяйств Армении в зависимости от высшего достигнутого уровня образования в домохозяйстве и наличия работающих членов в домохозяйстве, 2013-2017

\begin{tabular}{r|c|r|c|r}
\hline Год & Среднее и ниже & Выше среднего & $\begin{array}{c}\text { Нет работающих } \\
\text { членов }\end{array}$ & $\begin{array}{c}\text { Есть работающие } \\
\text { члены }\end{array}$ \\
\hline \multirow{2}{*}{2013} & 62,843 & $64,452^{* *}$ & $(0,000)$ & 63,890 \\
& & $65,154^{*}$ & 63,872 & $(0,936)$ \\
2014 & 64,719 & $(0,021)$ & 65,641 & $64,792^{* *}$ \\
& 65,248 & $65,857^{* *}$ & & $(0,000)$ \\
2015 & 65,478 & $66,277^{* *}$ & $(0,000)$ & $65,403^{* *}$ \\
& & $65,329^{*}$ & 66,300 & $(0,000)$ \\
2016 & 64,998 & $(0,041)$ & 65,335 & $(0,028)$ \\
& & & 65,805 & $65,010^{* *}$ \\
2017 & & & & $(0,000)$ \\
\hline
\end{tabular}

Источник: Расчеты автора на основе Комплексного обследования уровня жизни домашних хозяйств 8 Республике Армения.

Примечание: В скобках обозначена вероятность того, что различие между средними равно 0 (результат проверки гипотезы на статистическую значимость различий средних); значимость оченок на различных уровнях: *-на 5\%-ном, **-на 1\%-ном.

Таким образом, пол, возраст, семейное положение, наличие детей в домохозяйстве, уровень образования, доход и региональные отличия являются важными детерминантами структуры питания в ряде стран. 
Проверка значимости ряда из указанных факторов на уровне средних для качества питания домохозяйств Армении подтверждает выводы, полученные в академической литературе только частично: так, высокий уровень образования является положительный фактором качества питания домохозяйств, при этом наличие среди присутствующих членов домохозяйства работающих приводит к снижению показателя ИКП (таблица 7).

Ожидаемые эффекты дают факторы региональных различий и вовлеченности домохозяйства в сельское хозяйство: домохозяйства, отметившие, что кто-либо в их семье участвует в ведении сельского хозяйства (рассматривались в том числе и небольшие хозяйства на придомовых территориях), имели более низкий ИКП, чем те, которые свое участие в ведении сельского хозяйства отрицали. Аналогично наименьшее значение ИКП получено для жителей сельской местности, в то время как у жителей Еревана ИКП в среднем на 4 пункта выше, чем у жителей сельской местности, и на 2 - чем у жителей других городов страны. В последнем случае при анализе статистических различий средних в качестве базовых рассматривали средние значения ИКП для жителей городов (не включая Ереван) (таблица 8).

Таблица 8. Среднее значение ИКП домохозяйств Армении в зависимости от участия кого-либо из членов домохозяйства в сельском хозяйстве и от места проживания, 2013-2017

\begin{tabular}{|c|c|c|c|c|c|}
\hline Год & $\begin{array}{c}\text { Не участвует } \\
\text { в c/x }\end{array}$ & $\begin{array}{c}\text { Участвует } \\
\text { в c/x }\end{array}$ & $\begin{array}{l}\text { Сельская } \\
\text { местность }\end{array}$ & $\begin{array}{c}\text { Город } \\
\text { (не Ереван) }\end{array}$ & Ереван \\
\hline 2013 & 65,411 & $\begin{array}{r}61,957^{*} \\
(0,000)\end{array}$ & $\begin{array}{r}61,543 * \\
(0,000)\end{array}$ & 62,737 & $\begin{array}{r}68,538^{*} \\
(0,000)\end{array}$ \\
\hline 2014 & 65,722 & $\begin{array}{r}64,229^{*} \\
(0,000)\end{array}$ & $\begin{array}{c}64,099 \\
(0,127)\end{array}$ & 64,421 & $\begin{array}{r}67,013 * \\
(0,000)\end{array}$ \\
\hline 2015 & 66,631 & $\begin{array}{r}64,438^{*} \\
(0,000)\end{array}$ & $\begin{array}{r}64,283^{*} \\
(0,000)\end{array}$ & 65,441 & $\begin{array}{r}67,735^{*} \\
(0,000)\end{array}$ \\
\hline 2016 & 66,932 & $\begin{array}{r}64,912 * \\
(0,000)\end{array}$ & $\begin{array}{r}64,585^{*} \\
(0,000)\end{array}$ & 65,617 & $\begin{array}{r}68,413^{*} \\
(0,000)\end{array}$ \\
\hline 2017 & 66,210 & $\begin{array}{r}63,938^{*} \\
(0,000)\end{array}$ & $\begin{array}{r}63,717^{*} \\
(0,000)\end{array}$ & 64,925 & $\begin{array}{r}67,283^{*} \\
(0,000)\end{array}$ \\
\hline
\end{tabular}

Источник: Расчеты автора на основе Комплексного обследования уровня жизни домашних хозяйств 8 Республике Армения.

Примечание: В скобках обозначена вероятность того, что различие между средними равно 0 (результат проверки гипотезы на статистическую значимость различий средних); * — значимость оценок на 1\%-ном уровне; $c / x$ - сельское хозяйство.

Результаты, представленные в таблице 8, являются взаимодополняющими: по данным Обследования, ожидаемо наблюдается высокий уровень корреляции между участием в производстве собственной сельскохозяйственной продукции и проживанием в сельской местности (по расчетам автора, среднегодовое значение показателя составляет $0,750)$.

Наличие в домохозяйстве лиц старше и моложе трудоспособного возраста создает разнонаправленный эффект: домохозяйства, которые имеют в своем составе детей, демонстрируют более низкое качество питания, чем домохозяйства без детей, а наличие лиц старше трудоспособного возраста увеличивает ИКП домохозяйства (таблица 9). 
Если положительное влияние пожилых на качество питания в домохозяйстве является ожидаемым, то эффект наличия детей оказался обратным предсказываемому. С одной стороны, это может объясняться отсутствием контроля на другие факторы: так, согласно исследованиям, проведенным для Малайзии, качество питания детей не зависит от среднемесячного дохода их семьи, но дети, проживающие в сельской местности, в среднем питаются хуже, чем их сверстники из городов (Hau Chong et al. 2016: 67). С другой стороны, дети высоко восприимчивы к стилю питания родителей и могут способствовать закреплению хороших или плохих пищевых привычек в домохозяйстве (Al Yazeedi et al. 2021: 46). Для достижения ясности требуется проведение регрессионного анализа.

Таблица 9. Среднее значение ИКП домохозяйств Армении в зависимости от наличия в его составе детей до 16 лет включительно и пожилых старше 64 лет, 2013-2017

\begin{tabular}{|c|c|c|c|c|}
\hline Год & Нет детей & Есть дети & Нет пожилых & Есть пожилые \\
\hline 2013 & 64,118 & $\begin{array}{r}63,588 * \\
(0,008)\end{array}$ & 63,846 & $\begin{array}{r}63,947 \\
(0,614)\end{array}$ \\
\hline 2014 & 65,239 & $\begin{array}{r}64,715^{*} \\
(0,004)\end{array}$ & 64,925 & $\begin{array}{l}65,119 \\
(0,289)\end{array}$ \\
\hline 2015 & 65,898 & $\begin{array}{r}65,291^{*} \\
(0,001)\end{array}$ & 65,365 & $\begin{array}{r}66,044^{*} \\
(0,000)\end{array}$ \\
\hline 2016 & 66,317 & $\begin{array}{r}65,565^{*} \\
(0,000)\end{array}$ & 65,737 & $\begin{array}{r}66,367^{*} \\
(0,001)\end{array}$ \\
\hline 2017 & 65,536 & $\begin{array}{r}64,741 * \\
(0,000)\end{array}$ & 64,986 & $\begin{array}{r}65,498^{*} \\
(0,001)\end{array}$ \\
\hline
\end{tabular}

Источник: Расчеты автора на основе Комплексного обследования уровня жизни домашних хозяйств в Республике Армения.

Примечание: В скобках обозначена вероятность того, что различие между средними равно 0 (результат проверки гипотезы на статистическую значимость различий средних);

* - значимость оченок на 1\%-ном уровне.

Чтобы проиллюстрировать взаимосвязь дохода и уровня ИКП, был построен график на основе переменных логарифма среднедушевого дохода и ИКП с обозначением уровня плотности областей. В качестве единицы наблюдения брали домохозяйство, при этом величину дохода учитывали в размере на одного члена домохозяйства без поправки на его возраст и пол (рисунок 1). Доход учитывали в текущих ценах рассматриваемого года и без поправки на уровень жизни в регионе: эти же факторы определяют и значение ИКП соответствующих домохозяйств.

Мы наблюдаем значительную вариацию значений ИКП: люди, имеющие разный среднедушевой доход, могут иметь как качественное, так и некачественное питание. Однако уже здесь мы наблюдаем положительный характер связи показателей, о чем свидетельствует наклон линии тренда, хотя рост ИКП с увеличением дохода невелик - его оценка будет произведена в регрессионном анализе. 


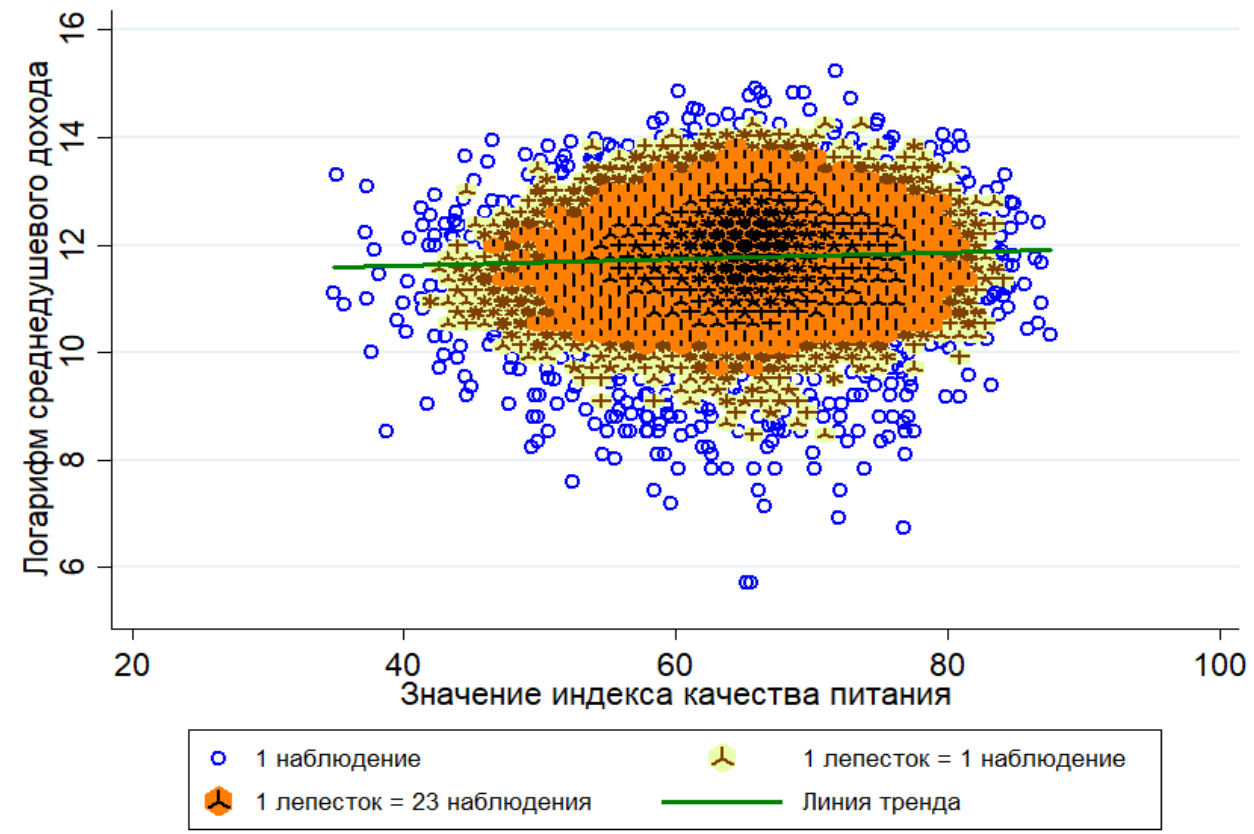

\section{Рисунок 1. Среднее значение ИКП домохозяйств Армении в зависимости от среднедушевого дохода каждого члена домохозяйства, 2013-2017}

Источник: Расчеть автора на основе Комплексного обследования уровня жизни домашних хозяйств в Республике Армения.

Полученные на данном уровне анализа результаты приводят к двум выводам. Во-первых, становится очевидным существование сложных взаимосвязей между факторами качества питания домохозяйств. Во-вторых, неполное объяснение вариаций ИКП через величину располагаемого дохода подчеркивает значимость немонетарных факторов для качества питания домохозяйств Армении.

\section{РЕГРЕССИОННЫЙ АНАЛИЗ СОЦИАЛЬНО-ЭКОНОМИЧЕСКИХ ФАКТОРОВ, ВЛИЯЮЩИХ НА ИНДЕКС КАЧЕСТВА ПИТАНИЯ}

С учетом рассмотренных в предыдущем разделе социально-экономических факторов, влияющих на качество питания домохозяйств, в итоговую спецификацию линейной регрессии помимо миграционных характеристик домохозяйства (наличия вернувшихся и невернувшихся мигрантов в спецификации 1 и наличия мигрантов в целом в спецификации 2) были включены логарифм среднедушевого дохода, параметры места проживания домохозяйства и участия его членов в сельском хозяйстве, высший достигнутый уровень образования, а также показатели численности домохозяйства (учитывали только присутствующих членов), долей в нем женщин, работающих членов трудоспособного возраста, детей и пожилых. Используемый в работе метод - МНКрегрессия на объединенной выборке. Для поправки на кросс-секционный характер данных включены фиктивные переменные года. За единицу учета брали домохозяйство.

Для учета структуры выборки при расчете стандартных ошибок было бы полезно провести кластеризацию ошибок. Однако данные обследования содержат показатель PSU 
(первичная единица наблюдения) только для раундов 2013 и 2014 г. Обе спецификации (с кластеризацией ошибок и без нее) для раундов 2013-2014 гг. дали идентичные результаты с незначительными отличиями в стандартных ошибках — их результаты представлены в таблице П2 Приложения. Высокая степень сходства стандартных ошибок двух спецификаций доказывает, что, несмотря на невозможность кластеризации ошибок на всем массиве, стандартные ошибки в регрессиях в таблицах 10 и 13 не переоценивают статистическую значимость коэффициентов.

В таблице 10 представлены результаты оценки двух спецификаций регрессии, различающихся бинарными переменными, связанными с миграцией: в первую спецификацию мы включаем бинарную переменную наличия мигрантов в целом, а во второй разбиваем мигрантов на две группы - вернувшихся и отсутствующих.

Таблица 10. Результаты оценки МНК-регрессии на объединенной выборке ИКП в зависимости от социально-экономических факторов, 2013-2017

\begin{tabular}{|c|c|c|}
\hline & $(1)$ & $(2)$ \\
\hline Количество членов домохозяйства & $\begin{array}{r}-0,111 * * \\
(0,0303)\end{array}$ & $\begin{array}{r}-0,111 * * \\
(0,0303)\end{array}$ \\
\hline Доля женщин & $\begin{array}{r}1,482 * * \\
(0,141)\end{array}$ & $\begin{array}{r}1,466 * * \\
(0,142)\end{array}$ \\
\hline Доля пожилых (старше 64 лет) & $\begin{array}{r}0,852 * * \\
(0,157)\end{array}$ & $\begin{array}{r}0,862 * * \\
(0,158)\end{array}$ \\
\hline Доля детей (не старше 16 лет) & $\begin{array}{r}-0,830 * * \\
(0,127)\end{array}$ & $\begin{array}{r}-0,832 * * \\
(0,127)\end{array}$ \\
\hline $\begin{array}{l}\text { Высший достигнутый уровень образования - выше } \\
\text { среднего }\end{array}$ & $\begin{array}{r}0,135 \\
(0,0865) \\
\end{array}$ & $\begin{array}{r}0,136 \\
(0,0865)\end{array}$ \\
\hline Доля работающих членов дх в возрасте 17-64 лет & $\begin{array}{r}0,345^{*} \\
(0,156)\end{array}$ & $\begin{array}{r}0,349 * \\
(0,156)\end{array}$ \\
\hline Логарифм среднедушевого дохода для каждого члена дх & $\begin{array}{r}0,214 * * \\
(0,0586)\end{array}$ & $\begin{array}{r}0,208 * * \\
(0,0589)\end{array}$ \\
\hline Наличие мигрантов & $\begin{array}{r}-0,593 * * \\
(0,138)\end{array}$ & \\
\hline Наличие вернувшихся мигрантов & & $\begin{array}{r}-0,713 * * \\
(0,187)\end{array}$ \\
\hline Наличие невернувшихся мигрантов & & $\begin{array}{r}-0,462^{*} \\
(0,190)\end{array}$ \\
\hline Проживают в Ереване & $\begin{array}{r}2,903 * * \\
(0,103)\end{array}$ & $\begin{array}{r}2,905 * * \\
(0,103)\end{array}$ \\
\hline Проживают в сельской местности & $\begin{array}{r}-0,650 * * \\
(0,125)\end{array}$ & $\begin{array}{r}-0,652 * * \\
(0,125)\end{array}$ \\
\hline Члены дх участвуют в сельском хозяйстве & $\begin{array}{r}-0,275^{*} \\
(0,124)\end{array}$ & $\begin{array}{r}-0,277 * \\
(0,124)\end{array}$ \\
\hline Набор фиктивных переменных года включен & & \\
\hline Константа & $\begin{array}{r}60,28 * * \\
(0,641)\end{array}$ & $\begin{array}{r}60,35 * * \\
(0,645)\end{array}$ \\
\hline Число наблюдений & 28471 & 28471 \\
\hline R2 & 0,082 & 0,082 \\
\hline
\end{tabular}

Источник: Расчеты автора на основе Комплексного обследования уровня жизни домашних хозяйств 8 Республике Армения.

Примечание: В скобках обозначена значимость оценок на различных уровнях: * — на 10\%-ном, ** —на 5\%-ном, ***-на 1\%-ном; дx-домохозяйство. 
В обеих спецификациях значимыми оказались практически все регрессоры, причем подавляющее большинство - на 1\%-ом уровне. Интересно отметить отрицательный знак при переменной наличия мигрантов в первом уравнении: таким образом предположение о том, что наличие в домохозяйстве мигрантов ведет к снижению значения ИКП, сформулированное на уровне анализа средних, подтвердилось. В то же время вторая спецификация показывает, что основной вклад в это вносят вернувшиеся мигранты. Заметим, что в регрессии есть контроль на доход в домохозяйстве, поэтому мы не можем объяснить обнаруженный эффект действием монетарного канала. Упоминавшиеся в литературе новые пищевые привычки могут быть одним из объяснений этого немонетарного механизма: культура питания другой страны может рассматриваться как более статусная, и приобщение к ней становится более интенсивным, когда мигрант возвращается на родину.

Для прочих социально-экономических факторов регрессионный анализ в целом подтвердил выводы, сделанные в предыдущем разделе работы. Коэффициент при регрессоре доли работающих членов оказался положительным, из чего мы можем заключить, что с поправкой на действие других факторов рост числа работающих членов в домохозяйстве положительно сказывается на качестве его питания. В то же время коэффициент при регрессоре доли детей оказался отрицательным, несмотря на учет фактора дохода и места проживания домохозяйства. Таким образом, в данном случае вновь срабатывает немонетарный механизм, в частности упоминавшаяся ранее высокая восприимчивость детей к негативным паттернам пищевого поведения кого-либо из родителей.

\section{ВЗАИМОСВЯЗЬ КАЧЕСТВА ПИТАНИЯ И СУБЪЕКТИВНОЙ ОЦЕНКИ УРОВНЯ БЛАГОСОСТОЯНИЯ ДОМОХОЗЯЙСТВА}

Еще одним существенным направлением анализа, которое позволяют реализовать данные Обследования, является оценка взаимосвязи ИКП и субъективной оценки домохозяйствами своего уровня благосостояния. В ходе Обследования респондентам задавали вопрос: «К какой категории (с точки зрения уровня благосостояния) относится ваша семья?». Распределение ответов на вопрос по годам представлено в таблице 11.

Мы объединили ответы «выше среднего» и «богатые», так как к последней группе себя относили в каждый год в среднем не более 40 респондентов.

По данным Обследования, показатель дохода на душу населения и финансовое самопозиционирование положительно, но слабо коррелированы: среднегодовое значение показателя - 0,2354, по расчетам автора. Данный парадокс можно объяснить тем, что, в отличие от объективной оценки уровня благосостояния, данный показатель выступает измерителем относительного положения домохозяйства в обществе. Финансовое самоощущение членов домохозяйств определяет, как они сами себя ранжируют в сравнении с другими домохозяйствами, и потому, помимо уровня объективного благосостояния, отражает систему ценностей: что для представителей данного общества означает высокий или низкий уровень благосостояния? Таким образом, расхождения в эффектах двух 
показателей могут сформировать представление о том, как те или иные факторы встроены в систему ценностей жителей Республики Армения, в том числе - качественное питание.

Таблица 11. Распределение ответов респондентов на вопрос: «К какой категории (с точки зрения уровня благосостояния) относится ваша семья?», 2013-2017, \% от общего числа ответов

\begin{tabular}{lrrrrrrrr}
\hline & 2013 & 2014 & 2015 & 2016 & 2017 & Всего \\
\hline \multirow{2}{*}{ Выше среднего } & 567 & 484 & 353 & 414 & 718 & 2535 \\
& $(4,4121)$ & $(3,7642)$ & $(2,8461)$ & $(3,1201)$ & $(3,4323)$ & $(3,5074)$ \\
\hline \multirow{2}{*}{ Средние } & 4977 & 5045 & 4674 & 4923 & 8935 & 28554 \\
& $(38,7285)$ & $(39,2363)$ & $(37,6844)$ & $(37,1015)$ & $(42,7614)$ & $(39,5069)$ \\
\hline \multirow{2}{*}{ Ниже среднего } & 5161 & 5437 & 5617 & 5939 & 8658 & 30812 \\
& $(40,1603)$ & $(42,2850)$ & $(45,2874)$ & $(44,7585)$ & $(41,4358)$ & $(42,6310)$ \\
\hline \multirow{2}{*}{ Бедные } & 1748 & 1616 & 1522 & 1813 & 2341 & 9076 \\
& $(13,6021)$ & $(12,5681)$ & $(12,2712)$ & $(13,6634)$ & $(11,2036)$ & $(12,5574)$ \\
\multirow{2}{*}{ Очень бедные } & 362 & 277 & 237 & 180 & 243 & 1299 \\
& $(2,8169)$ & $(2,1543)$ & $(1,9108)$ & $(1,3565)$ & $(1,1630)$ & $(1,7973)$ \\
\multirow{2}{*}{ Всего } & 12851 & 12858 & 12403 & 13269 & 20895 & 72276 \\
& $(100,00)$ & $(100,00)$ & $(100,00)$ & $(100,00)$ & $(100,00)$ & $(100,00)$ \\
\hline
\end{tabular}

Источник: Расчеты автора на основе Комплексного обследования уровня жизни домашних хозяйств 8 Республике Армения.

Примечание: В скобках обозначена доля от общего числа ответов, \%.

Анализ средних значений ИКП по группам самопозиционирования показывает, что в большинстве случаев отличия статистически значимы (референтная группа - те, кто позиционирует себя как средних по уровню благосостояния), при этом заметно, что те, кто относит себя к уровню выше среднего, имеют более низкие значения ИКП, чем те, кто позиционирует себя как средних, ниже среднего и даже бедных (за исключением 2013 г.). В 2015 и 2016 г. наиболее высокие значения ИКП имели домохозяйства, позиционирующие себя как бедные и очень бедные соответственно (таблица 12).

Таблица 12. Среднее значение ИКП домохозяйств Армении в зависимости от финансового самопозиционирования, 2013-2017

\begin{tabular}{|c|c|c|c|c|c|}
\hline Год & Очень бедные & Бедные & Ниже среднего & Средний & Выше среднего \\
\hline 2013 & $\begin{array}{c}63,458 \\
(0,655)\end{array}$ & $\begin{array}{r}62,938^{*} \\
(0,070)\end{array}$ & $\begin{array}{r}64,041 * * * \\
(0,000)\end{array}$ & 63,289 & $\begin{array}{r}64,255 * * * \\
(0,001)\end{array}$ \\
\hline 2014 & $\begin{array}{r}63,688 * * \\
(0,036) \\
\end{array}$ & $\begin{array}{r}64,702 \\
(0,314) \\
\end{array}$ & $\begin{array}{r}64,769 * * \\
(0,038) \\
\end{array}$ & 64,515 & $\begin{array}{r}64,628 \\
(0,709) \\
\end{array}$ \\
\hline 2015 & $\begin{array}{r}64,145 * * * \\
(0,005)\end{array}$ & $\begin{array}{r}65,689 * * \\
(0,042)\end{array}$ & $\begin{array}{r}65,395 \\
(0,491)\end{array}$ & 65,311 & $\begin{array}{r}63,766 * * * \\
(0,000)\end{array}$ \\
\hline 2016 & $\begin{array}{r}66,657^{*} \\
(0,055) \\
\end{array}$ & $\begin{array}{r}66,449 * * * \\
(0,000) \\
\end{array}$ & $\begin{array}{r}65,688 \\
(0,729) \\
\end{array}$ & 65,731 & $\begin{array}{r}64,078 * * * \\
(0,000) \\
\end{array}$ \\
\hline 2017 & $\begin{array}{r}64,570 \\
(0,967) \\
\end{array}$ & $\begin{array}{r}65,685 * * * \\
(0,000)\end{array}$ & $\begin{array}{r}65,077 * * * \\
(0,000)\end{array}$ & 64,552 & $\begin{array}{r}64,598 \\
(0,860) \\
\end{array}$ \\
\hline
\end{tabular}

Источник: Расчеты автора на основе Комплексного обследования уровня жизни домашних хозяйств в Республике Армения.

Примечание: В скобках обозначена вероятность того, что различие между средними равно 0 (результат проверки гипотезы на статистическую значимость различий средних); значимость оценок на различных уровнях: *-на 10\%-ном, **_на 5\%-ном, ***-на 1\%-ном. 
Для корректировки на ранее исследованные факторы, добавим бинарные переменные финансового самопозиционирования в спецификации МНК-регрессии (1) и (2). В качестве референтной группы возьмем тех, кто позиционирует уровень благосостояния своего домохозяйства как средний (таблица 13).

Таблица 13. Результаты оценки МНК-регрессии на объединенной выборке ИКП в зависимости от социально-экономических факторов и финансового самопозиционирования, 2013-2017

\begin{tabular}{|c|c|c|}
\hline & $(3)$ & $(4)$ \\
\hline Число членов домохозяйства & $\begin{array}{r}-0,0764 * * \\
(0,0322)\end{array}$ & $\begin{array}{r}-0,0763 * * \\
(0,0322)\end{array}$ \\
\hline Доля женщин & $\begin{array}{r}1,758 * * * \\
(0,153)\end{array}$ & $\begin{array}{r}1,759 * * * \\
(0,153)\end{array}$ \\
\hline Доля пожилых (старше 64 лет) & $\begin{array}{r}0,841 * * * \\
(0,166)\end{array}$ & $\begin{array}{r}0,841 * * * \\
(0,166)\end{array}$ \\
\hline Доля детей (не старше 16 лет) & $\begin{array}{r}-0,883 * * * \\
(0,144)\end{array}$ & $\begin{array}{r}-0,883 * * * \\
(0,144)\end{array}$ \\
\hline $\begin{array}{l}\text { Высший достигнутый уровень образования - выше } \\
\text { среднего }\end{array}$ & $\begin{array}{r}0,157 * \\
(0,0928)\end{array}$ & $\begin{array}{r}0,157 * \\
(0,0928)\end{array}$ \\
\hline Доля работающих членов дх в возрасте 17-64 лет & $\begin{array}{r}0,291 * \\
(0,168)\end{array}$ & $\begin{array}{r}0,292^{*} \\
(0,168)\end{array}$ \\
\hline Логарифм среднедушевого дохода для каждого члена дх & $\begin{array}{r}0,255^{* * * *} \\
(0,0652)\end{array}$ & $\begin{array}{r}0,255^{* * * *} \\
(0,0652)\end{array}$ \\
\hline Наличие мигрантов & $\begin{array}{r}-0,638 * * * \\
(0,196)\end{array}$ & \\
\hline Наличие вернувшихся мигрантов & & $\begin{array}{r}-0,628 * * * \\
(0,196) \\
\end{array}$ \\
\hline Наличие невернувшихся мигрантов & & $\begin{array}{r}-1,433 \\
(3,734)\end{array}$ \\
\hline Проживают в Ереване & $\begin{array}{r}2,670 * * * \\
(0,110) \\
\end{array}$ & $\begin{array}{r}2,670 * * * \\
(0,110) \\
\end{array}$ \\
\hline Проживают в сельской местности & $\begin{array}{r}-0,596^{* * *} \\
(0,132) \\
\end{array}$ & $\begin{array}{r}-0,597 * * * \\
(0,132) \\
\end{array}$ \\
\hline Члены дх участвуют в сельском хозяйстве & $\begin{array}{r}-0,302 * * \\
(0,132)\end{array}$ & $\begin{array}{r}-0,301 * * \\
(0,132)\end{array}$ \\
\hline $\begin{array}{l}\text { Субъективная оценка благосостояния - выше среднего и } \\
\text { богатые }\end{array}$ & $\begin{array}{r}-0,272 \\
(0,237)\end{array}$ & $\begin{array}{r}-0,272 \\
(0,237)\end{array}$ \\
\hline Субъективная оценка благосостояния - ниже среднего & $\begin{array}{r}0,318 * * * \\
(0,0947)\end{array}$ & $\begin{array}{r}0,318 * * * * \\
(0,0947)\end{array}$ \\
\hline Субъективная оценка благосостояния - бедные & $\begin{array}{r}0,624 * * * \\
(0,132)\end{array}$ & $\begin{array}{r}0,624 * * * * \\
(0,132)\end{array}$ \\
\hline Субъективная оценка благосостояния - очень бедные & $\begin{array}{r}0,292 \\
(0,296)\end{array}$ & $\begin{array}{r}0,292 \\
(0,296)\end{array}$ \\
\hline Набор фиктивных переменных года включен & & \\
\hline Константа & $\begin{array}{r}59,25 * * * \\
(0,728)\end{array}$ & $\begin{array}{r}59,25 * * * \\
(0,728)\end{array}$ \\
\hline Число наблюдений & 25107 & 25107 \\
\hline R2 & 0,081 & 0,081 \\
\hline
\end{tabular}

Источник: Расчеты автора на основе Комплексного обследования уровня жизни домашних хозяйств в Республике Армения.

Примечание: В скобках обозначена значимость оченок на различных уровнях: * — на 10\%-ном, ** —на 5\%-ном, ***_на 1\%-ном; дх-домохозяйство.

Введение новых переменных в регрессию незначительно повлияло на оценки коэффициентов при прочих регрессорах, в том числе связанных с миграцией. При этом мы 
наблюдаем интересный эффект: позиционирующие себя как очень бедных и богатых статистически неотличимы от средних, а вот те, кто оценивает свой уровень благосостояния ниже среднего и на уровне бедных, питаются лучше. Причем у бедных это отличие значительнее: увеличение ИКП в этой группе больше. Это может быть обусловлено тем, что домохозяйства, ощущающие себя относительно богатыми, не задумываются о качестве питания или не воспринимают его как детерминанту здоровья. С ростом уровня благосостояния домохозяйства получают больше возможностей по выбору стиля питания, но в данном случае он явно оказывается менее качественным - домохозяйства предпочитают дорогие и нездоровые продукты питания или направляют дополнительный доход в иные сферы, не меняя свое пищевое поведение. Выявление конкретных механизмов этого выбора является направлением будущих исследований.

\section{ЗАКЛЮЧЕНИЕ}

В ходе проведенного исследования для Республики Армения было выявлено, что участие домохозяйств в миграции приводит к снижению среднего значения ИКП домохозяйств, причем эффект преимущественно достигается за счет наличия в домохозяйстве возвратных мигрантов. Учитывая то, что разница в доходах не объясняет наблюдаемые различия, подтверждаются предположения о наличии немонетарного канала воздействия миграции на качество питания домохозяйств, в качестве одной из возможных реализаций которого может выступать трансляция образа питания, привнесенного мигрантами из других стран. Полученные результаты стимулируют дальнейшую разработку темы: в частности, было бы полезным проведение качественного исследования пищевых привычек домохозяйств вернувшихся на родину мигрантов до и после миграции. Кроме того, нельзя отрицать существование проблемы неслучайности возвращения мигрантов: возможно, найденные взаимосвязи объясняются иными, общими для них причинами.

Также результаты регрессионного анализа и анализа на уровне средних показали, что значимыми для оценки качества питания являются социально-экономические факторы, традиционно рассматриваемые в литературе, а именно уровень дохода и образования, различные характеристики состава домохозяйства, проживание в сельской или городской местности. При этом эффекты практически всех показателей соответствовали предсказанным. Исключение составил фактор роста доли детей, который в случае с Арменией оказывает редко наблюдаемое отрицательное воздействие. Вероятной причиной здесь может быть все тот же канал передачи пищевых привычек, которые дети активно перенимают от родителей, что также является интересным направлением для более детальной разработки.

Включение в анализ переменной субъективной оценки уровня благосостояния домохозяйства привело к выводу о том, что качественное питание в соответствии с со стандартами, признаваемыми на международном уровне, не является однозначно воспринимаемой детерминантой здоровья в массовом сознании жителей республики: показатель ИКП тех, кто оценивает свой уровень благосостояния ниже среднего или как бедных, оказался выше, чем у тех, кто относит себя к очень бедному, среднему или 
высокому уровню благосостояния. Полученные результаты выявили интересные взаимосвязи с учетом социальной неоднородности населения, уточнение механизмов которых требует дальнейшего изучения пищевых привычек и системы ценностей жителей Республики Армения на качественном уровне.

\section{ЛИТЕРАТУРА}

Мартинчик А.Н. (2019). Индексы качества питания как инструмент интегральной оценки рациона питания, Вопросы питания, 88(3), 5-12. DOI: https://doi.org/10.24411/00428833-2019-10024.

Оксиненко В.Г. (2021). Расчет индекса качества питания для домохозяйств Армении. Демографические исследования: сборник статей, 29, 118-137. Москва: Экономический факультет Московского государственного университета им. М.В. Ломоносова.

Al Yazeedi B., Berry D.C., Crandell J., Waly M. (2021). Family Influence on Children's Nutrition and Physical Activity Patterns in Oman. Journal of Pediatric Nursing, 56, 42-48. DOI: https://doi.org/10.1016/j.pedn.2020.07.012

Azagba S., Sharaf M.F. (2011). Disparities in the frequency of fruit and vegetable consumption by socio-demographic and lifestyle characteristics in Canada. Journal of the American Dietetic Association. DOI: https://doi.org/10.1016/s0002-8223(99)00080-2.

Azzarri C., Zezza A. (2011). International migration and nutritional outcomes in Tajikistan. Food Policy, 36(1), 54-70. DOI: https://doi.org/10.1016/j.foodpol.2010.11.004.

Bansak C, Chezum B. (2009). How Do Remittances Affect Human Capital Formation of SchoolAge Boys and Girls? The American Economic Review, 99 (2), 145-148. Retrieved from https://www.jstor.org/stable/25592390

Bedrosian S. (2019). Typical Diet in Armenia Is No Longer Healthy; Nutrition Specialist Points to Good and Bad Influences from Other Cultures. URL: https://hetq.am/en/article/102022

Bernstein A.M., Bloom D.E., Rosner B.A., Franz M., Willett W.C. (2010). Relation of food cost to healthfulness of diet among US women. The American journal of clinical nutrition, 92(5), 1197-1203. DOI: https://doi.org/10.3945/AJCN.2010.29854.

Burggraf C., Teuber R., Brosig S., Glauben T. (2015). Economic growth and the demand for dietary quality: Evidence from Russia during transition. Economics and Human Biology, 19, 184-203. DOI: https://doi.org/10.1016/j.ehb.2015.08.002.

Chong K.H., Wu S.K., Noor Hafizah Y., Bragt M.C.., Poh B.K. (2016). Eating Habits of Malaysian Children. Asia Pacific Journal of Public Health, 28(5), 59-74. DOI: https://doi.org/10.2307/26686287.

Darmon N., Drewnowski A. (2008). Does social class predict diet quality? American Journal of Clinical Nutrition, 87(5), 1107-1117. DOI: https://doi.org/10.1093/ajcn/87.5.1107.

Dave D.M., Kelly I.R. (2012). How does the business cycle affect eating habits? Social Science and Medicine, 74(2), 254-262. DOI: https://doi.org/10.1016/j.socscimed.2011.10.005.

Guenther P., Juan W., Lino M., Hiza H., Fungwe T., Lucas R. (2009). Diet Quality of Lowincome and Higher-income Americans in 2003-2004 as Measured by the Healthy Eating Index-2005. The FASEB Journal, 23(S1), 2003-2005. DOI:

https://doi.org/10.1096/fasebj.23.1_supplement.540.5. 
Hildebrandt N., McKenzie D. J., Esquivel G., Schargrodsky E. (2005). The Effects of Migration on Child Health in Mexico. Academy of Management Review, 1, 257-289. Retrieved from https://www.jstor.org/stable/20065490

Hiza H.A., Casavale K.O., Guenther P.M., Davis C.A. (2013). Diet Quality of Americans Differs by Age, Sex, Race/Ethnicity, Income, and Education Level. Journal of the Academy of Nutrition and Dietetics, 113(2), 297-306. DOI: https://doi.org/10.1016/j.jand.2012.08.011.

Huffman S.K., Rizov M. (2018). Life satisfaction and diet in transition: evidence from the Russian Longitudinal Monitoring Survey. Agricultural Economics (United Kingdom), 49(5), 563-574. DOI: https://doi.org/10.1111/agec.12442.

Krebs-Smith S., Pannucci T.-R., Subar A., Kirkpatrick S., Lerman J., Tooze J., Wilson M., Reedy J. (2015). Update of the Healthy Eating Index: HEI-2015. Journal of the Academy of Nutrition and Dietetics, 9, 1591 - 1602. DOI: https://doi.org/ 10.1016/j.jand.2018.05.021

Lei L., Desai S., Chen F. (2020). Fathers' migration and nutritional status of children in India: Do the effects vary by community context? Demographic Research, 43(December), 545579. DOI: https://doi.org/10.4054/DemRes.2020.43.20.

Mangiavacchi L., Piccoli L. (2018). Parental alcohol consumption and adult children's educational attainment. Economics \& Human Biology, 28, 132-145, DOI: https://doi.org/10.1016/j.ehb.2017.12.006

Mansour W., Chaaban J., Litchfield J. (2011). The impact of migrant remittances on school attendance and education attainment: Evidence from Jordan. International Migration Review, 45(4), 812-851. DOI: https://doi.org/10.1111/j.1747-7379.2011.00869.x.

Marchetta F., Sim S. (2021). The effect of parental migration on the schooling of children left behind in rural Cambodia. World Development, 146. DOI: https://doi.org/10.1016/j.worlddev.2021.105593.

Massin S., Kopp P. (2014). Is life satisfaction hump-shaped with alcohol consumption? Evidence from Russian panel data. Addictive Behaviors, 39(4), 803-810. DOI: https://doi.org/10.1016/j.addbeh.2014.01.005.

Rosenzweig M. R., Stark O. (1989). Consumption Smoothing, Migration, and Marriage: Evidence from Rural India. Journal of Political Economy, 97 (4), 905-926. DOI: https://doi.org/10.1086/261633

Shen W., Hu L. C., Hannum E. (2021). Effect pathways of informal family separation on children's outcomes: Paternal labor migration and long-term educational attainment of leftbehind children in rural China. Social Science Research, 97. DOI: https://doi.org/ 10.1016/j.ssresearch.2021.102576.

Xie F., Zhu Sh., Cao M., Kang X., Du J. (2019). Does rural labor outward migration reduce household forest investment? The experience of Jiangxi, China. Forest Policy and Economics, 101, 62-69. DOI: https://doi.org/10.1016/j.forpol.2019.01.010. 
A NON-MONETARY LINK BETWEEN INTERNATIONAL MIGRATION AND THE NUTRITIONAL STATUS OF MIGRANT HOUSEHOLDS (USING THE REPUBLIC OF ARMENIA AS AN EXAMPLE)

\author{
VALERIIA OKSINENKO
}

\begin{abstract}
The article analyzes migration as a factor in the nutritional quality of a migrant's household members remaining in their home country. To assess the quality of nutrition, we calculate a comprehensive nutritional quality index based on the 2015 USDA Center for Food Policy Center HEI methodology. We use the data of the Integrated Household Survey of the Republic of Armenia for 2013-2017. As a result of regression analysis and analysis at the average level, it is revealed that the quality of household nutrition is negatively affected by there being migrants in general, and particularly by the presence of returned migrants. Since differences in income do not explain the difference, we conclude that there is a non-monetary influence of migration on household nutrition. Along the way, the work verifies the findings in the literature concerning the positive impact on nutrition of the presence of women, the elderly, and children, as well as that of living in a big city and having a high level of education and income - all correlations were confirmed for households in the Republic of Armenia. In addition, we include in the analysis a subjective assessment of households' financial condition: households positioning themselves as poorer have higher nutritional quality index values than those who identify themselves as middle class or rich. The differences found lead to the conclusion that the quality of food is not included in the system of key values in Armenian society: when there is an opportunity to choose the style of food, households make a choice for the worse.
\end{abstract}

Key words: migration, Armenia, households' nutrition, return migration, well-being of migrant households.

VALERIIA OKSINENKo (leraoksinenko@gmail.com), Lomonosov Moscow State University, Russia.

THE RESEARCH WAS MADE WITHIN THE PROJECT FUNDED BY THE RUSSIAN FOUNDATION FOR BASIC RESEARCH (RFBR), No. 20-310-90017.

DATE RECEIVED: SEPTEMBER 2021.

\title{
REFERENCES
}

Al Yazeedi B., Berry D.C., Crandell J., Waly M. (2021). Family Influence on Children's Nutrition and Physical Activity Patterns in Oman. Journal of Pediatric Nursing, 56, 42-48. DOI: https://doi.org/10.1016/j.pedn.2020.07.012

Azagba S., Sharaf M.F. (2011). Disparities in the frequency of fruit and vegetable consumption by socio-demographic and lifestyle characteristics in Canada. Journal of the American Dietetic Association. DOI: https://doi.org/10.1016/s0002-8223(99)00080-2.

Azzarri C., Zezza A. (2011). International migration and nutritional outcomes in Tajikistan. Food Policy, 36(1), 54-70. DOI: https://doi.org/10.1016/j.foodpol.2010.11.004.

Bansak C, Chezum B. (2009). How Do Remittances Affect Human Capital Formation of SchoolAge Boys and Girls? The American Economic Review, 99 (2), 145-148. Retrieved from https://www.jstor.org/stable/25592390

Bedrosian S. (2019). Typical Diet in Armenia Is No Longer Healthy; Nutrition Specialist Points to Good and Bad Influences from Other Cultures. URL: https://hetq.am/en/article/102022 
Bernstein A.M., Bloom D.E., Rosner B.A., Franz M., Willett W.C. (2010). Relation of food cost to healthfulness of diet among US women. The American journal of clinical nutrition, 92(5), 1197-1203. DOI: https://doi.org/10.3945/AJCN.2010.29854.

Burggraf C., Teuber R., Brosig S., Glauben T. (2015). Economic growth and the demand for dietary quality: Evidence from Russia during transition. Economics and Human Biology, 19, 184-203. DOI: https://doi.org/10.1016/j.ehb.2015.08.002.

Chong K.H., Wu S.K., Noor Hafizah Y., Bragt M.C.., Poh B.K. (2016). Eating Habits of Malaysian Children. Asia Pacific Journal of Public Health, 28(5), 59-74. DOI: https://doi.org/10.2307/26686287.

Darmon N., Drewnowski A. (2008). Does social class predict diet quality? American Journal of Clinical Nutrition, 87(5), 1107-1117. DOI: https://doi.org/10.1093/ajcn/87.5.1107.

Dave D.M., Kelly I.R. (2012). How does the business cycle affect eating habits? Social Science and Medicine , 74(2), 254-262. DOI: https://doi.org/10.1016/j.socscimed.2011.10.005.

Guenther P., Juan W., Lino M., Hiza H., Fungwe T., Lucas R. (2009). Diet Quality of Lowincome and Higher-income Americans in 2003-2004 as Measured by the Healthy Eating Index-2005. The FASEB Journal, 23(S1), 2003-2005. DOI: https://doi.org/10.1096/fasebj.23.1_supplement.540.5.

Hildebrandt N., McKenzie D. J., Esquivel G., Schargrodsky E. (2005). The Effects of Migration on Child Health in Mexico. Academy of Management Review, 1, 257-289. Retrieved from https://www.jstor.org/stable/20065490

Hiza H.A., Casavale K.O., Guenther P.M., Davis C.A. (2013). Diet Quality of Americans Differs by Age, Sex, Race/Ethnicity, Income, and Education Level. Journal of the Academy of Nutrition and Dietetics, 113(2), 297-306. DOI: https://doi.org/10.1016/j.jand.2012.08.011.

Huffman S.K., Rizov M. (2018). Life satisfaction and diet in transition: evidence from the Russian Longitudinal Monitoring Survey. Agricultural Economics (United Kingdom), 49(5), 563-574. DOI: https://doi.org/10.1111/agec.12442.

Krebs-Smith S., Pannucci T.-R., Subar A., Kirkpatrick S., Lerman J., Tooze J., Wilson M., Reedy J. (2015). Update of the Healthy Eating Index: HEI-2015. Journal of the Academy of Nutrition and Dietetics, 9, 1591 - 1602. DOI: https://doi.org/ 10.1016/j.jand.2018.05.021

Lei L., Desai S., Chen F. (2020). Fathers' migration and nutritional status of children in India: Do the effects vary by community context? Demographic Research, 43(December), 545579. DOI: https://doi.org/10.4054/DemRes.2020.43.20.

Mangiavacchi L., Piccoli L. (2018). Parental alcohol consumption and adult children's educational attainment. Economics \& Human Biology, 28, 132-145, DOI: https://doi.org/10.1016/j.ehb.2017.12.006

Mansour W., Chaaban J., Litchfield J. (2011). The impact of migrant remittances on school attendance and education attainment: Evidence from Jordan. International Migration Review, 45(4), 812-851. DOI: https://doi.org/10.1111/j.1747-7379.2011.00869.x.

Marchetta F., Sim S. (2021). The effect of parental migration on the schooling of children left behind in rural Cambodia. World Development, 146. DOI: https://doi.org/10.1016/j.worlddev.2021.105593.

Martinchik A.N. (2019). Indices of diet quality as a tool for integrated assessment of dietary intakeю Voprosy Pitaniia, 88(3), 5-12. (In Russ.). DOI: https://doi.org/10.24411/0042-88332019-10024. 
Massin S., Kopp P. (2014). Is life satisfaction hump-shaped with alcohol consumption? Evidence from Russian panel data. Addictive Behaviors, 39(4), 803-810. DOI: https://doi.org/10.1016/j.addbeh.2014.01.005.

Oksinenko V.G. (2021). Raschet indeksa kachestva piyaniya domokhozaystv Armenii [Calculation of the food quality index for households in Armenia]. Demograficheskiye issledovania: sbornik statey, 29, 118-137. Moscow: Faculty of Economics, Lomonosov Moscow State University. (In Russ.).

Rosenzweig M. R., Stark O. (1989). Consumption Smoothing, Migration, and Marriage: Evidence from Rural India. Journal of Political Economy, 97 (4), 905-926. DOI: https://doi.org/10.1086/261633

Shen W., Hu L. C., Hannum E. (2021). Effect pathways of informal family separation on children's outcomes: Paternal labor migration and long-term educational attainment of leftbehind children in rural China. Social Science Research, 97. DOI: https://doi.org/ 10.1016/j.ssresearch.2021.102576.

Xie F., Zhu Sh., Cao M., Kang X., Du J. (2019). Does rural labor outward migration reduce household forest investment? The experience of Jiangxi, China. Forest Policy and Economics, 101, 62-69. DOI: https://doi.org/10.1016/j.forpol.2019.01.010. 


\section{ПРИЛОЖЕНИЕ}

Таблица П1. Объемы среднедушевого потребления основных групп продуктов питания в Республике Армения в $2013-2017$ гг.

\begin{tabular}{|c|c|c|c|c|c|c|c|c|c|c|}
\hline & \multicolumn{2}{|c|}{2013} & \multicolumn{2}{|l|}{2014} & \multicolumn{2}{|c|}{2015} & \multicolumn{2}{|c|}{2016} & \multicolumn{2}{|c|}{2017} \\
\hline & $\begin{array}{l}\text { Диапазон } \\
\text { значений }\end{array}$ & Среднее & $\begin{array}{l}\text { Диапазон } \\
\text { значений }\end{array}$ & Среднее & $\begin{array}{l}\text { Диапазон } \\
\text { значений }\end{array}$ & Среднее & $\begin{array}{l}\text { Диапазон } \\
\text { значений }\end{array}$ & Среднее & $\begin{array}{l}\text { Диапазон } \\
\text { значений }\end{array}$ & Среднее \\
\hline Фрукты & $0-4773,85$ & 219,76 & $0-2848,98$ & 180 & $0-1915,8$ & 190,31 & $0-2420,01$ & 199,03 & $0-3448,44$ & 179,51 \\
\hline Овощи & $0-2084,4$ & 465,73 & $30-2566,84$ & 511,84 & $0-2919,83$ & 529,04 & $0-4210,1$ & 538,2 & $0-3273,59$ & 510,3 \\
\hline Мясо & $0-8408,70$ & 1499,04 & $0-7502,81$ & 1382,429 & $0-6124,65$ & 1346,32 & $0-6872,93$ & 1388,86 & $0-7104,89$ & 1393,76 \\
\hline Молочные продукты & $0-1650,6$ & 259,24 & $0-1835,95$ & 347,72 & $0-2159,40$ & 374,76 & $0-1847,68$ & 373,48 & $0-2412,53$ & 368,54 \\
\hline Цельные злаки & $0-3102,84$ & 284,76 & $0-1336,4$ & 240,35 & $0-1405,28$ & 241,18 & $0-2839,2$ & 270,33 & $0-1978,35$ & 224,8 \\
\hline $\begin{array}{l}\text { Рыба и } \\
\text { морепродукты }\end{array}$ & $0-5110$ & 106,4 & $0-1038,38$ & 49,6 & $0-1108,82$ & 39,7 & $0-1413,57$ & 46,96 & $0-2323$ & 44,5 \\
\hline Мучные изделия & $\begin{array}{r}208,87- \\
12328,35\end{array}$ & 2809,87 & $\begin{array}{r}312,66- \\
10734,45\end{array}$ & 2733,61 & $\begin{array}{l}234,04- \\
7205,35\end{array}$ & 2763,22 & $\begin{array}{l}432,6- \\
8913,1\end{array}$ & 2781,36 & $\begin{array}{l}198,75- \\
9107,06\end{array}$ & 2604,87 \\
\hline
\end{tabular}

Источник: Расчеты автора на основе Комплексного обследования уровня жизни домашних хозяйств в Республике Армения. 
Таблица П2. Результаты оценки МНК-регрессии на объединенной выборке ИКП от социально-экономических факторов, 2013-2014 гг., с кластеризацией ошибок (1 и 3) и без нее (2 и 4)

\begin{tabular}{|c|c|c|c|c|}
\hline & ИКП (1) & ИКП (2) & ИКП (3) & ИКП (4) \\
\hline \multirow{2}{*}{ Количество членов домохозяйства } & $-0,102 *$ & $-0,102 *$ & $-0,102 * *$ & $-0,102 *$ \\
\hline & $(0,0440)$ & $(0,0537)$ & $(0,0442)$ & $(0,0537)$ \\
\hline \multirow{2}{*}{ Доля женщин } & $1,244 * * *$ & $1,244 * * *$ & $1,260 * * *$ & $1,260 * * *$ \\
\hline & $(0,176)$ & $(0,225)$ & $(0,164)$ & $(0,227)$ \\
\hline \multirow{2}{*}{ Доля пожилых (старше 64 лет) } & $0,639 *$ & $0,639 * *$ & $0,632 *$ & $0,632 * *$ \\
\hline & $(0,323)$ & $(0,259)$ & $(0,329)$ & $(0,259)$ \\
\hline \multirow{2}{*}{ Доля детей (не старше 16 лет) } & $-0,875 * * *$ & $-0,875 * * *$ & $-0,876^{* * *}$ & $-0,876^{* * *}$ \\
\hline & $(0,122)$ & $(0,198)$ & $(0,123)$ & $(0,198)$ \\
\hline \multirow{2}{*}{$\begin{array}{l}\text { Высший достигнутый уровень образования - } \\
\text { выше среднего }\end{array}$} & $0,253 * *$ & $0,253^{*}$ & $0,253 * *$ & $0,253^{*}$ \\
\hline & $(0,107)$ & $(0,144)$ & $(0,106)$ & $(0,144)$ \\
\hline \multirow{2}{*}{ Доля работающих членов дх в возрасте 17-64 лет } & $0,455^{* *} *$ & $0,455^{*}$ & $0,453 * *$ & $0,453^{*}$ \\
\hline & $(0,166)$ & $(0,251)$ & $(0,168)$ & $(0,251)$ \\
\hline \multirow{2}{*}{$\begin{array}{l}\text { Логарифм среднедушевого дохода для каждого } \\
\text { члена дх }\end{array}$} & $0,488 * * *$ & $0,488 * * *$ & $0,493 * * *$ & $0,493 * * *$ \\
\hline & $(0,0636)$ & $(0,0999)$ & $(0,0646)$ & $(0,100)$ \\
\hline \multirow{2}{*}{ Наличие мигрантов } & $-0,411$ & $-0,411 *$ & & \\
\hline & $(0,237)$ & $(0,231)$ & & \\
\hline \multirow{2}{*}{ Наличие вернувшихся мигрантов } & & & $-0,276$ & $-0,276$ \\
\hline & & & $(0,401)$ & $(0,328)$ \\
\hline \multirow{2}{*}{ Наличие невернувшихся мигрантов } & & & $-0,525$ & $-0,525^{*}$ \\
\hline & & & $(0,367)$ & $(0,304)$ \\
\hline \multirow{2}{*}{ Проживают в Ереване } & $3,966 * * *$ & $3,966 * * *$ & $3,966 * * *$ & $3,966 * * *$ \\
\hline & $(0,198)$ & $(0,169)$ & $(0,199)$ & $(0,169)$ \\
\hline \multirow{2}{*}{ Проживают в сельской местности } & $-0,460 * *$ & $-0,460 * *$ & $-0,460 * *$ & $-0,460 * *$ \\
\hline & $(0,182)$ & $(0,206)$ & $(0,182)$ & $(0,206)$ \\
\hline \multirow{2}{*}{ Члены дх участвуют в сельском хозяйстве } & $-0,125$ & $-0,125$ & $-0,120$ & $-0,120$ \\
\hline & $(0,241)$ & $(0,202)$ & $(0,245)$ & $(0,203)$ \\
\hline \multicolumn{2}{|l|}{ Фиктивная переменная года включена } & & & да \\
\hline \multirow{2}{*}{ Константа } & $57,00 * * *$ & $57,00 * * *$ & $56,93 * * *$ & $56,93 * * *$ \\
\hline & $(0,696)$ & $(1,088)$ & $(0,699)$ & $(1,094)$ \\
\hline Число наблюдений & 10350 & 10350 & 10350 & 10350 \\
\hline $\mathrm{R} 2$ & 0,108 & 0,108 & 0,108 & 0,108 \\
\hline
\end{tabular}

Источник: Расчеты автора на основе Комплексного обследования уровня жизни домашних хозяйств в Республике Армения.

Примечание: В скобках обозначена значимость оченок на различных уровнях: * — на 10\%-ном, ** —на 5\%-ном, ***_-на 1\%-ном; дх-домохозяйство. 